\title{
Buğdayda (Triticum aestivum L.) Erken Alüminyum Stresine Karşı Bakteri Uygulamalarının Etkileri
}

\author{
Farzaneh PORDEL $^{1^{*} \text { (D) Arash HOSSEIN POUR }}{ }^{1 \text { (i) }}$ Ramazan ÇAKMAKÇI ${ }^{2}$ (D) \\ ${ }^{1}$ Atatürk Üniversitesi, Ziraat Fakültesi, Tarla Bitkileri Bölümü, Erzurum, Türkiye \\ ${ }^{2}$ Çanakkale Onsekiz Mart Üniversitesi, Ziraat Fakültesi, Tarla Bitkileri Bölümü, Çanakkale, Türkiye \\ ('Sorumlu yazar e-mail: farzanehpordale@ yahoo.com) \\ DOI: 10.17097/ataunizfd.431400 \\ Geliş Tarihi (Received Date): 16.03.2018 \\ Kabul Tarihi (Accepted Date): 02.11.2018
}

\begin{abstract}
ÖZ: Buğday; taşınması, tarımı, saklanma ve işlenmesinin oldukça kolay olması; kışlık ve yazlık üretilebilmesi ve besin değerinin yüksek olması gibi nedenlerle, dünyada ve Türkiye'de temel besin maddelerinden birini olușturmaktadır. Bu çalıșmada buğdayda (Triticum aestivum L. cv Kırık) erken aluminyum stresine karşı bakteri uygulamalarının etkileri buğday çimlenme parametreleriyle araştırılmıştır. Araştırma tesadüf parsellerinde 5 farklı alüminyum chloride konsantrsyonu $(0,7,5,15,22,5$ ve 30 $\mathrm{mM}) \times 11$ (farklı bakteri) faktöriyel deneme desenine göre 4 tekrarlı olarak yürütülmüştür. Sterilize edilen buğday tohumları 24 saat sıvı besi yerinde geliştirilmiş farklı bakteri türleri içerisinde tohum kodlaması yapılmış̧ır. Ardından tohumlara alüminyum chloride $\left(\mathrm{AlCl}_{3}\right)$ uygulanarak karanlık fotoperyot ortamında $20^{\circ} \mathrm{C}$ 'de 10 gün süreyle kağıt üzerinde çimlendirilmiștir. Bu çalıșma sonunda çimlenme oranı (ÇO), çimlenme hızı katsayısı (ÇHK), ortalama çimlenme zamanı (OÇZ), çimlenme gücü indeksi (ÇGI), toplam embriyonal kök uzunluğu ve sürgün uzunluğu parametreleri ölçülmüştür. $\mathrm{AlCl}_{3}{ }^{\prime}$ in konsantrasyonu artıkça tüm bakteri uygulamalarında çimlenme oranı, çimlenme hızı kat sayısı, çimlenme gücü indeksi, kök uzunluğu ve sürgün uzunluğu çok önemli derecede azalmış buna karşın ortalama çimlenme zamanı uzamıştır. Farklı bakteri uygulamalarının buğdayda alüminyum stresine karşı verdiği tepkiler değerlendirildiğinde, Pseudomonas fluorescens bakterisi așılamasının, diğer uygulamalara göre daha iyi sonuç verdiği ve test edilen çimlenme karakterleri bakımdan alüminyumun olumsuz etkisinin azaltılmasında etkili olduğu belirlenmiștir.
\end{abstract}

Anahtar Kelimeler: Alüminyum, Bakteri, Buğday, Çimlenme, Stres

\section{Effects of Differential Bacteria Application on Early Aluminum Stress in Wheat (Triticum aestivum L.)}

\begin{abstract}
Wheat, transport, cultivation, storage and processing are very easy; winter and summer produce, and high nutritional value of reasons such as; in the world and in Turkey constitutes one of the essential nutrients. In this study, the effects of different bacterial applications on different germination parameters of aluminum stress were aimed, this study was conducted in 4 replicates according to the completely randomized factorial design. As the plant material, the seeds of the wheat (Triticum aestivum L.cv. Kırik) were used. Sterilized wheat seeds seed coding was done in 11 different bacterial species developed in liquid medium for 24 hours. The seeds were then germinated on paper in dark photoperiod formed with aluminum chloride $\left(\mathrm{AlCl}_{3}\right)$ for 10 days at $20^{\circ} \mathrm{C}$. At the end of this study, the germination rate (GR), germination rate coefficient (CVG), mean germination time (MGT), germination vigor index (GVI), total embryonic root length and shoot length parameters were measured. The germination rate, germination vigor index, germination rate, root length and shoot length decreased significantly in all bacterial applications with different concentration of $\mathrm{AlCl} 3$, whereas mean germination time was prolonged. When the responses of different bacterial inoculations against aluminum stress in wheat were evaluated, inoculation with Pseudomonas fluorescens was found to be better than other applications and it was found to be effective in reducing the negative effect of aluminum in terms of tested germination characteristics.
\end{abstract}

Keywords: Aluminum, Bacteria, Wheat, Germination, Stress

\section{GíRiş}

Buğday insanlığın en önemli besin kaynağı olan stratejik bir bitkidir. Artan gıda ihtiyacına karşılık dünya buğday üretiminde azalmaların meydana gelmesi, üretiminin sürdürülebilirliği ve besin güvencesi konusundaki endişelerle birlikte buğday fiyatları da artırmaktadır. Buğday dünyada ekim alanı en fazla olan ve dünya nüfusunun 1/3'ünün besinlerden aldığı kalorinin \%50'den fazlasını, proteinin ise yaklaşık yarısını karşılayan stratejik bir bitkidir. Doğayı kirleten unsurlardan biri olan ağır metallerin bitkilerin vejetatif organlarını fizyolojik olarak etkilediği bilinmektedir. Bitkilerin ağır metal toksiditesine karşı toleransları; bitki türüne, element türüne, strese maruz kalma süresine ve strese maruz kalan doku veya organın yapısına bağlı olarak değişmektedir (Stresty and Madhava Rao, 1999).

Toprak asitliği, kök büyümesini ve bitkisel üretimi azaltmakta; $\mathrm{Al}, \mathrm{Mn}$ ve çeşitli katyonları ve ayrıca $\mathrm{Ca}, \mathrm{Mg}, \mathrm{P}$, Mo ve $\mathrm{Si}$ noksanlıklarına yol açabilmektedir. $\mathrm{Bu}$ etkiler, Al'in, farklı bitki genotiplerinde ve stres koşullarında diğer iyonlarla etkileşimleriyle daha da karmaşıklaşmaktadır (Foy, 1992). Düşük pH düzeylerinde, Al çözünürlüğüne bağlı olarak, bitkilerin çeşitli besin eksikliği belirtileri gösterdiği, azaltılmış kök sistemi ve sonuçta verim düşüşü meydana geldiği bilinmektedir. Al toksisitesi önemli bir tarımsal problemdir ve bitki sistemlerinde yoğun olarak araştırılmaktadır. Alüminyumun bitki büyümesi, ürün verimi, besin 
maddesi alımı ve dağılımı üzerindeki etkileri vejetatif ve üreme organlarında hala tam olarak anlaşılmamıştır (Baker et al., 2000).Bitki gelişmesini teşvik eden bakteriler (PGPR) son yıllarda bitkisel üretimde biyogübre olarak kullanılmaktadırlar. $\mathrm{Bu}$ bakterilerin, azot fiksasyonu vasıtasıyla bitkinin azot beslenmesini, fosforun çözünürlüğünü, su kullanım etkinliğini ve bitkisel hormon üretimini (oksin, stokinin ve giberallin) arttırdı ğ 1 , besin elementlerinin bitki tarafından alımını etkinleştirerek veya bitkide etilen seviyesini azaltarak bitki gelişimi üzerine olumlu etki yaptığı tespit edilmiştir (Schiller et al., 1995).

Araştırmalarda, Variovorax, Methylobacterium, Burkholderia, Okibacterium, Rhodococcus, Microbacterium, Sphingomonas, Curtobacterium, Serratia, Pseudomonas, Ralstonia, Staphylococcus, Bacillus, Arthrobacter, Paenibacillus, Chryseobacterium ve Leifsonia cinslerine ait birçok türün farklı strainlerinin metal toleransı gösterdiği rapor edilmiştir (Idris et al., 2004; Belimov et al., 2005; Dell'Amico et al., 2005; Barzanti et al., 2007; Jiang et al., 2008; Kuffner et al., 2010; Benmalek et al., 2014). Bu izolatlardan bazılarının metal ile kirlenmiş topraklara aşılanarak bitki yetiştiriciliğinde kullanılması önerilmiştir. Bu bakterilerin, bitkilerin kök bölgesinden (rizosferden) ya da Thlaspi goingense, Graminaceae, Allysum bertolonii, Zea mays, Salix caprea bitkilerinin dokularından izole edilerek nikel, kadmiyum, kurşun ve çinkoya karşı kullanılması ile bitki toleransını artırabildiği bildirilmiştir (Belimov et al., 2005; Barzanti et al., 2007; Jiang et al., 2008; Kuffner et al., 2010). Bu çalışmada bakteri uygulamalarının alüminyum stresine etkisinin çimlenme parametrelerinde belirlenmesi amaçlanmıştır.

\section{MATERYAL VE METOT \\ Materyal}

Araştırmada bitki materyali olarak ekmeklik buğday (Triticum aestivum L.) Kırik genotipi tohumları kullanılmış, aşılama işlemi için 11 bakteri türüne ait streinler Atatürk Üniversitesi Ziraat Fakültesi Tarla Bitkileri Bölümünden temin edilerek kullanılmıştır (Çizelge 1).

Çizelge 1. Deneme konuları, kullanılan bakteri kod, tür ismi, izolayon kaynağı, azot bağlama ve fosfor çözme özellikleri

\begin{tabular}{|c|c|c|c|c|c|}
\hline Sira & $\begin{array}{c}\text { Bakteri } \\
\text { kodu }\end{array}$ & Tür ismi & $\begin{array}{c}\text { İzolasyon } \\
\text { kaynağ1 }\end{array}$ & $\begin{array}{c}\text { Azot } \\
\text { fiksetme }\end{array}$ & $\begin{array}{c}\text { Fosfat } \\
\text { çözme }\end{array}$ \\
\hline 0 & 0 & Kontrol (Bakterisiz) & & & \\
\hline 1 & $2 / 2$ & Paenibacillus polymyxa & Buğday & + & + \\
\hline 2 & $4 / 8$ & Rhodococcus erythropolis & Yulaf & + & $\mathrm{K}^{+}$ \\
\hline 3 & $8 / 4$ & Pseudomonas fluorescens & Çay & + & $\mathrm{K}^{+}$ \\
\hline 4 & $8 / 6$ & Pseudomonas fluorescens & A̧ay & $\mathrm{K}^{+}$ & + \\
\hline 5 & $9 / 4$ & Rhodococcus erythropolis & Arpa & + & + \\
\hline 6 & $29 / 2$ & Pseudomonas putida & Asma & $\mathrm{K}^{+}$ & $\mathrm{Z}^{+}$ \\
\hline 7 & $53 / 5$ & Pseudomonas putida & Kekik & + & + \\
\hline 8 & $\mathrm{R} 2 / 1$ & Variovorax paradoxus & Ahududu & + & $\mathrm{K}^{+}$ \\
\hline 9 & $\mathrm{R} 2 / 2$ & Paenibacillus polymyxa & Ahududu & $\mathrm{K}^{+}$ & + \\
\hline 10 & $\mathrm{~T} 26$ & Pseudomonas fluorescens & & & + \\
\hline
\end{tabular}

+ :pozitif, $\mathrm{K}^{+}$:kuvvetli pozitif, $\mathrm{Z}^{+}$: kuvvetli pozitif

\section{Metot}

Tohumlar musluk suyunda yıkandiktan sonra \%70'lik etil alkolde (EtOH) 3 dakika karıştırılıp \%20 sodyum hipokloritte $15 \mathrm{dk}$ bekletilmiştir. $\mathrm{Bu}$ işlem sonrasında tohumlar steril kabin içerisinde 3 defa steril saf suyla yıkanmış ve yüzey sterilizasyonu yapılmıştır. Nutrient Agar (NA) besi ortamında 24 saatlik bakteri kültürlerinden bir öze dolusu alınarak $200 \mathrm{ml}$ Nutrient Broth (NB) içerisine inoküle edilmiş ve bir gece yatay çalkalayıcıda $30{ }^{\circ} \mathrm{C}$ 'de 150 $\mathrm{rpm} / \mathrm{dk}$ 'da inkübasyona bırakılmıştır. Daha sonra bakteri konsantrasyonu $10^{8}$ hücre/ml olacak şekilde spektrofotometre ile ayarlanarak yüzey sterilizasyonu yapılmış tohumlar bakteri ile aşılanmıştır. Kontrol grup için steril tohumlar bakterisiz NB içerisinde bekletilmiştir (Heinonsalo et al., 2004). Tohumlar kuruduktan sonra $\mathrm{AlCl}_{3}$ ile oluşturulmuş 5 farklı alüminyum konsantrasyonunda [0 kontrol (saf su), $7,5,15,22,5$ ve $30 \mathrm{mM}$ ] çözeltiler hazırlanmıştır. Petri kutuları UV 1 şı altında $15 \mathrm{dk}$ bekletilmiş, ekimi yapılacak olan kağıtlar ise $121^{\circ} \mathrm{C}$ 'de $15 \mathrm{dk}$ steril edilmiştir. Tohumlar içerisinde iki çimlenme kâğıdı (1 numaralı watman kâğıdı) arasında hazırlanan petri kutularında çimlendirmeye alınmışlardır. Her petri kutusuna 25 adet tohum ve bunların üzerine farkl $\mathrm{AlCl}_{3}$ konsantrasyon çözeltisinden $15 \mathrm{ml}$ konulmuştur. $\mathrm{Bu}$ işlemin ardından tohumlar 16:8 saat 1şık:karanlık fotoperyotta $20^{\circ} \mathrm{C}$ 'de çimlendirmeye alınmışlardır. 


\section{Çimlenme ve fide ile ilgili karakterler}

\section{Çimlenme ile ilgili karakterler}

Tohumlar çimlendirme ortamında konulduktan sonra 14 gün süreyle her gün sayım yapılmak suretiyle, çimlenme oranı aşağıdaki eşitlik aracılığ ile hesaplanmıştır (AOSA, 1983);

Çimlenme oranı $(\%)=($ Çimlenen toplam tohum sayıs1/toplam tohum sayıs1) x 100

Çimlenme hızı katsayısı (ÇHK); Formülde Ti, denemenin başladığı günden itibaren gün sayısı, $\mathrm{Ni}$ ise gün başına çimlenen tohum sayısı (Maguire, 1962) olmak üzere:

ÇHK $=\sum \mathrm{Ni} / \sum \mathrm{NiTi} \times 100$

Ortalama çimlenme zamanı (OÇZ); Ortalama çimlenme zamanı aşağıdaki formüle göre hesaplanmıştır. Formüldeki f, sayım günündeki çimlenen tohum sayısını; $x$, sayım yapılan gün sayısını göstermektedir (Dezfuli et al., 2008).

$\mathrm{OÇZ}($ gün $)=\Sigma(\mathrm{fx}) / \Sigma \mathrm{f}$

Çimlenme gücü indeksi (ÇGI): Çimlenme gücü indeksini hesaplamak için aşağıdaki formül temel alınmıştır (Abdul-Baki and Anderson 1970):

ÇGİ = (ortalama sürgün uzunluğu + ortalama kök uzunluğu) $\times$ toplam çimlenme yüzdesi.

\section{Fide ile ilgili karakterler}

Tohumlar çimlendirme ortamına konulduktan sonra 14. günün sonunda her petri kutusundan 10 'ar fide şansa bağlı olarak alınmış ve bunlarda;

Toplam embriyonal kök uzunluğu (cm): Embriyonal köklerin milimetrik cetvel ile ölçülmesi ile belirlenmiştir.

Sürgün uzunluğu (cm): Bitkinin tohum ile yaprak ucu arasındaki uzunluğun milimetrik cetvelle ölçülmesiyle elde edilmiştir.

\section{Verilerin Analizi}

Elde edilen veriler tesadüf parsellerinde 4 (farklı $\mathrm{AlCl}_{3}$ ) x 11 (farklı bakteri) faktöriyel deneme desenine göre SPSS-20 istatistik paket programı kullanılarak varyans analizine tabi tutulmuş ve uygulamalar Duncan çoklu karşılaştırma testi ile karşılaştırılmıştır.

\section{BULGULAR}

\section{Çimlenme oranı (ÇO)}

Farklı bakteri ve Al uygulamalarının ve bu iki faktör arasındaki interaksiyonun çimlenme oranı üzerine etkisi çok önemli $(\mathrm{P} \leq 0.01)$ olmuştur (Çizelge 2). Bakterilere göre yapılan değerlendirilmede $\mathrm{Al}$ uygulama ortalamalarına göre, en yüksek çimlenme oranının $\% 76,5$ ile 6 numaralı bakteride, en düşük çimlenme oranının ise $\% 40,5$ oranı ile kontrol (bakterisiz) uygulamasında belirlenmiştir (Çizelge 3). Alüminyum konsantrasyonlarına göre, en yüksek çimlenme oranı kontrol $(0 \mathrm{mM})$ uygulamasinda \%80,6 olarak tespit edilmiş, bunu azalan sıra ile $15 \mathrm{mM}(\% 77,08)$ ve 7,5 $\mathrm{mM}(\% 75,20), 30 \mathrm{mM}(\% 43,33)$ ve $22,5 \mathrm{mM}$ $(\% 39,79)$ konsantrasyonları izlemiştir.

Farklı bakteri ve Al uygulamalarının interaksiyonlarının etkisi, buğdayın çimlenme oranı üzerine farklılık göstermiştir. $\mathrm{Bu}$ nedenle Bakteri $\times \mathrm{Al}$ interaksiyonu önemli $(\mathrm{P} \leq 0.01)$ bulunmuştur (Çizelge 2). En yüksek çimlenme oranı 4 nolu bakteri $+7,5$ $\mathrm{mM} \mathrm{Al}, 11$ nolu bakteri $+7,5 \mathrm{mM}$ uygulamalarda $\% 100$ oranıyla elde edilirken; en düşük çimlenme oranı kontrol (bakterisiz) $+30 \mathrm{mM}$ uygulamasinda $\% 17,50$ olarak tespit edilmiştir (Çizelge 3).

\section{Çimlenme hızı katsayısı (ÇHK)}

Farklı bakteri ve Al uygulamalarının ve bu iki faktör arasındaki interaksiyonun çimlenme hızı katsayısı üzerine etkisi çok önemli $(\mathrm{P} \leq 0.01)$ bulunmuştur (Çizelge 2). Bakterilere göre yapılan değerlendirmede ortalamalar esas alınarak, en yüksek çimlenme oranı katsayısı 51,32 ile 4 numaralı bakteride, en düşük çimlenme oranı katsayısı ise 27,89 oranı ile 10 numaralı bakteri uygulamasında belirlenmiştir (Çizelge 3). Alüminyum konsantrasyonlarına göre, en yüksek çimlenme oranı katsayısı $(22,5 \mathrm{mM})$ uygulamasinda, $\% 38,10$ olarak tespit edilmiş, bunu azalan sıra ile $7,5 \mathrm{mM}(\% 35,56)$ ve $30 \mathrm{mM}(\% 34,52), 15 \mathrm{mM}(\% 32,10)$ ve $0 \mathrm{mM}$ $(\% 31,95)$ konsantrasyonları izlemiştir (Çizelge 3).

Farklı bakteri ve Al uygulamaları intraksiyonlarının etkisi çimlenme oranı katsayısı üzerine farklllık göstermiş ve bu nedenle bakteri $\times \mathrm{Al}$ interaksiyonunun etkisi çok önemli $(\mathrm{P} \leq 0.01)$ olmuştur (Çizelge 2). En yüksek çimlenme oranı katsayıs 4 nolu bakteri $+22,5 \mathrm{mM} \mathrm{Al}$ uygulamada $\% 71,42$ oranıyla elde edilirken; en düşük çimlenme oranı katsayıs1 7 nolu bakteri $+22,5 \mathrm{mM}$ uygulamasında $\% 22,27$ olarak tespit edilmiştir (Çizelge 3).

\section{Ortalama çimlenme zamanı (OÇZ) (gün)}

Farklı bakteri ve Al uygulamalarının ve bu iki faktör arasındaki interaksiyonun ortalama çimlenme zamanı üzerine etkisi önemsiz olmuştur (Çizelge 2). Bakterilere göre yapılan değerlendirmede ortalamalar esas alınarak, en yüksek ortalama çimlenme zamanı 3,78 gün ile 10 numaralı bakteride, en düşük ortalama çimlenme zamanı ise 2,51 gün ile kontrol uygulamasında belirlenmiş̦tir (Çizelge 3). Alüminyum konsantrasyonlarına göre, en yüksek ortalama çimlenme zamanı kontrol $\left(\begin{array}{lll}0 & \mathrm{mM})\end{array}\right.$ uygulamasında 3,35 gün olarak tespit edilmiş, bunu azalan sira ile $15 \mathrm{mM}(3,34$ gün) ve $30 \mathrm{mM}(3,14$ gün), 7,5 mM (3,05 gün) ve 22,5 $\mathrm{mM}$ (2,78 gün) konsantrasyonları izlemiştir.

Farklı bakteri ve Al uygulamalarının interaksiyonlarının etkisi ortalama çimlenme zamanı 
üzerine farklılık göstermemiştir (Çizelge 2). En yüksek ortalama çimlenme zamanı 5 nolu bakteri + 7,5 mM Al uygulamasında 4,66 gün elde edilirken; en düşük ortalama çimlenme zamanı 4 nolu bakteri + $30 \mathrm{mM}$ uygulamasinda 1,78 gün olarak tespit edilmiştir (Çizelge 3).

\section{Çimlenme gücü indeksi (ÇGí)}

Farklı bakteri ve Al uygulamalarının ve bu iki faktör arasındaki interaksiyonun çimlenme gücü indeksi üzerine etkisi çok önemli $(\mathrm{P} \leq \quad 0.01)$ bulunmuştur (Çizelge 2). Bakterilere göre yapılan değerlendirmede ortalamalar esas alınarak, en yüksek çimlenme gücü indeksi 1004,0 ile 11 numaralı bakteride, en düşük çim gücü indeksi ise 204,7 oranı ile kontrol (Bakterisiz) uygulamasında belirlenmiştir (Çizelge 3).

Alüminyum konsantrasyonlarına göre, en yüksek çimlenme gücü indeksi kontrol (0 mM) uygulamasında, 1230,9 olarak tespit edilmiş; bunu azalan sira ile 7,5 $\mathrm{mM}(1082,9)$ ve $15 \mathrm{mM}(684,7)$, $30 \mathrm{mM}(101,8)$ ve $22.5 \mathrm{mM}(72,1)$ konsantrasyonları izlemiştir (Çizelge 3).

Çimlenme gücü indeksi üzerine farklı bakteri ve Al uygulamalarının etkisi farklılık göstermiş ve bu nedenle Bakteri $\times \mathrm{Al}$ interaksiyonunun etkisi çok önemli ( $\mathrm{P} \leq 0.01)$ bulunmuştur (Çizelge 2).

En yüksek çimlenme gücü indeksi 11 nolu bakteri + 0 mM Al uygulamasıyla 2028,80 oranıla elde edilirken; en düşük çimlenme gücü indeksi 5 nolu bakteri $+30 \mathrm{mM}$ uygulamalarda 13,05 olarak tespit edilmiştir (Çizelge 3).

\section{Toplam embriyonal kök uzunluğu (cm)}

Farklı bakteri ve Al uygulamalarının ve bu iki faktör arasındaki interaksiyonun toplam embriyonal kök uzunluğu üzerine etkisi çok önemli $(\mathrm{P} \leq 0.01)$ olmuştur (Çizelge 2). Bakterilere göre yapılan değerlendirmede ortalamalar esas alınarak, en yüksek toplam embriyonal kök uzunluğu $5,56 \mathrm{~cm}$ ile 11 numaralı bakteride, en düşük toplam embriyonal kök uzunluğu ise $1,53 \mathrm{~cm}$ ile kontrol uygulamasında belirlenmiştir (Çizelge 3).
Alüminyum konsantrasyonlarına göre, en yüksek toplam embriyonal kök uzunluğu kontrol (0 $\mathrm{mM}$ ) uygulamasında $7,37 \mathrm{~cm}$ olarak belirlenmiş; bunu azalan sira ile 7,5 $\mathrm{mM}(6,63 \mathrm{~cm}), 15 \mathrm{mM}(3,25$ $\mathrm{cm}), 30 \mathrm{mM}(0,88 \mathrm{~cm})$ ve $22,5 \mathrm{mM}(0,58 \mathrm{~cm})$ konsantrasyonları izlemiştir (Çizelge 3). Toplam embriyonal kök uzunluğu üzerine farklı bakteri ve $\mathrm{Al}$ uygulamalarının etkisi farlılık göstermiş; bu nedenle Bakteri $\times \mathrm{Al}$ interaksiyonunun etkisi çok önemli $(\mathrm{P} \leq$ 0.01 ) olmuştur (Çizelge 2).

En yüksek toplam embriyonal kök uzunluğu 8 nolu bakteri $+0 \mathrm{mM}$ Al uygulamasında 9,97 $\mathrm{cm}$ elde edilirken; en düşük toplam embriyonal kök uzunluğu ise 5 nolu bakteri $+30 \mathrm{mM} \mathrm{Al} \mathrm{kombinasyonunda}$ $(0,08 \mathrm{~cm})$ tespit edilmiştir (Çizelge 3$)$.

\section{Sürgün uzunluğu (cm)}

Farklı bakteri ve Al uygulamalarının ve bu iki faktör arasındaki interaksiyonun sürgün uzunluğu üzerine etkisi çok önemli $(\mathrm{P} \leq 0.01)$ olmuştur (Çizelge 2). Bakterilere göre yapılan değerlendirmede ortalamalar esas alınarak, en yüksek sürgün uzunluğu $5,31 \mathrm{~cm}$ ile 4 numaralı bakteride, en düşük sürgün uzunluğu ise $2,34 \mathrm{~cm}$ ile kontrol uygulamasında belirlenmiştir (Çizelge 3).

Alüminyum konsantrasyonlarına göre, en yüksek sürgün uzunluğu kontrol $\left(\begin{array}{ll}0 & \mathrm{mM}\end{array}\right)$ uygulamasında $6,67 \mathrm{~cm}$ olarak tespit edilmiş, bunu azalan sira ile 7,5 $\mathrm{mM}(6,59 \mathrm{~cm}), 15 \mathrm{mM}(5,09 \mathrm{~cm})$, $30 \mathrm{mM} \quad(1,38 \mathrm{~cm})$ ve $22,5 \mathrm{mM} \quad(0,89 \mathrm{~cm})$ konsantrasyonları izlemiştir (Çizelge 3).

Farklı bakteri ve $\mathrm{Al}$ uygulamalarının interaksiyonlarının etkisi sürgün uzunluğu üzerine farklılık göstermiştir. $\mathrm{Bu}$ nedenle Bakteri $\times \mathrm{Al}$ interaksiyonunun etkisi çok önemli $(\mathrm{P} \leq$ 0.01) bulunmuştur (Çizelge 2). En yüksek sürgün uzunluğu 4 nolu bakteri $+7,5 \mathrm{mM}$ Al uygulamada 9,17 cm olarak ölçülmüşken; en düşük sürgün uzunluğu kontrol + $30 \mathrm{mM}$ uygulamalarda $0,38 \mathrm{~cm}$ olarak tespit edilmiştir (Çizelge 3).

Çizelge 2. Buğdayda farklı bakteri ve Al ve konsantrasyonlarının çimlenme ile ilgili bazı karakterlere ait varyans analizi sonuçları

\begin{tabular}{|c|c|c|c|c|c|c|c|}
\hline $\begin{array}{c}\text { Varyasyon } \\
\text { Kaynağı }\end{array}$ & SD & ÇO & ÇHK & OÇZ & ÇGI & KU & SU \\
\hline $\begin{array}{c}\text { Bakteri } \\
\text { Uygulamas } 1\end{array}$ & 11 & $2569,51^{* *}$ & $862,35^{* *}$ & $4,28^{* *}$ & $1479610,66^{* *}$ & $36,69^{* *}$ & $22,00^{* *}$ \\
\hline Al Stresi & 4 & $18998,54^{* *}$ & $316,06^{*}$ & $2,64^{* *}$ & $13912134,73^{* *}$ & $479,19^{* *}$ & $378,46^{* *}$ \\
\hline Bakteri $\times \mathrm{Al}$ & 44 & $930,59^{* *}$ & $268,74^{* *}$ & 0,90 & $446619,25^{* *}$ & $13,56^{* *}$ & $11,06^{* *}$ \\
\hline Hata & 180 & 241,25 & 147,38 & 0,72 & 56484,01 & 1,87 & 1,27 \\
\hline Toplam & 240 & & & & & & \\
\hline
\end{tabular}

\footnotetext{
$* \mathrm{p}<0.05 ; * *: \mathrm{p}<0.01$ düzeyinde önemlidir.
} 
Çizelge 3. Bakteri ve Al uygulamalarının çimlenme oranı (ÇO), çimlenme hızı katsayısı (ÇHK), ortalama çimlenme zamanı (OÇZ), çimlenme gücü indeksi (ÇGİ), toplam embriyonal kök uzunluğu (cm) ve sürgün uzunluğu $(\mathrm{cm})$ üzerine etkisi

\begin{tabular}{|c|c|c|c|c|c|c|c|}
\hline Bakteri No & $\begin{array}{c}\text { Al Stress } \\
(\mathrm{mM})\end{array}$ & $\begin{array}{l}\text { ÇO } \\
(\%)\end{array}$ & ÇHK & $\begin{array}{l}\text { OÇZ } \\
\text { (gün) }\end{array}$ & ÇGI & $\begin{array}{l}\mathrm{KU} \\
(\mathbf{c m})\end{array}$ & $\begin{array}{l}\mathrm{SU} \\
(\mathbf{c m})\end{array}$ \\
\hline \multirow{6}{*}{0} & 0 & $65,0^{a^{*}}$ & $32,32^{a}$ & 3,15 & $379,6^{\mathrm{a}}$ & $2,35^{a}$ & $3,17^{\mathrm{a}}$ \\
\hline & 7,5 & $42,5^{a b c}$ & $58,90^{\text {a }}$ & 1,96 & $267,3^{\mathrm{a}}$ & $2,52^{a}$ & $3,73^{\mathrm{a}}$ \\
\hline & 15,0 & $47,5^{a b}$ & $40,62^{a}$ & 2,64 & $305,5^{\mathrm{a}}$ & $1,93^{a}$ & $3,59^{\mathrm{a}}$ \\
\hline & 22,5 & $30,0^{b c}$ & $51,73^{a}$ & 2,47 & $47,9^{b}$ & $0,57^{b}$ & $0,85^{b}$ \\
\hline & 30,0 & $17,5^{\mathrm{c}}$ & $25,34^{\mathrm{a}}$ & 2,31 & $23,4^{b}$ & $0,30^{b}$ & $0,38^{b}$ \\
\hline & Ortalama & $40,5^{E}$ & $41,79^{B}$ & $2,51^{\mathrm{DE}}$ & $204,7^{\mathrm{G}}$ & $1,53^{D}$ & $2,34^{\mathrm{F}}$ \\
\hline \multirow{6}{*}{1} & 0 & $82,5^{a}$ & $31,88^{\mathrm{a}}$ & 3,35 & $1444,9^{\mathrm{a}}$ & $8,98^{a}$ & $8,24^{\mathrm{a}}$ \\
\hline & 7,5 & $97,5^{\mathrm{a}}$ & $36,23^{a}$ & 2,84 & $1567,6^{\mathrm{a}}$ & $8,34^{\mathrm{a}}$ & $7,64^{\mathrm{a}}$ \\
\hline & 15,0 & $90,0^{\mathrm{a}}$ & $45,35^{\mathrm{a}}$ & 2,40 & $785,9^{b}$ & $2,90^{b}$ & $5,92^{b}$ \\
\hline & 22,5 & $30,0^{b}$ & $32,19^{a}$ & 1,80 & $35,1^{\mathrm{c}}$ & $0,30^{c}$ & $0,56^{\mathrm{c}}$ \\
\hline & 30,0 & $32,5^{b}$ & $39,07^{\mathrm{a}}$ & 2,70 & $40,8^{c}$ & $0,53^{c}$ & $0,80^{\mathrm{c}}$ \\
\hline & Ortalama & $66,5^{\mathrm{ABC}}$ & $36,95^{\mathrm{BC}}$ & $2,62^{\mathrm{CDE}}$ & $774,9^{\mathrm{BC}}$ & $4,21^{\mathrm{B}}$ & $4,63^{\mathrm{ABC}}$ \\
\hline \multirow{6}{*}{2} & 0 & $97,5^{\mathrm{a}}$ & $29,17^{b}$ & 3,51 & $1537,0^{\mathrm{a}}$ & $8,01^{a}$ & $7,72^{\mathrm{a}}$ \\
\hline & 7,5 & $85,0^{b}$ & $33,93^{b}$ & 2,96 & $1208,6^{b}$ & $7,60^{a}$ & $6,53^{b}$ \\
\hline & 15,0 & $90,0^{a b}$ & $31,5^{b}$ & 3,17 & $949,7^{b}$ & $4,55^{b}$ & $6,02^{b}$ \\
\hline & 22,5 & $55,0^{\mathrm{c}}$ & $53,05^{\mathrm{a}}$ & 2,10 & $142,9^{\mathrm{c}}$ & $1,30^{\mathrm{c}}$ & $1,28^{\mathrm{c}}$ \\
\hline & 30,0 & $47,50^{\mathrm{c}}$ & $31,67^{b}$ & 3,56 & $66,2^{c}$ & $0,45^{c}$ & $0,79^{\mathrm{c}}$ \\
\hline & Ortalama & $75,0^{A}$ & $35,88^{\mathrm{BCD}}$ & $3,07^{\text {BCD }}$ & $780,9^{\mathrm{BC}}$ & $4,38^{B}$ & $4,47^{B C}$ \\
\hline \multirow{6}{*}{3} & 0 & $82,5^{a}$ & $34,05^{\mathrm{a}}$ & 2,95 & $1665,6^{\mathrm{a}}$ & $11,43^{a}$ & $8,87^{\mathrm{a}}$ \\
\hline & 7,5 & $57,5^{b}$ & $29,09^{a}$ & 3,62 & $858,6^{b}$ & $7,30^{b}$ & $7,15^{a}$ \\
\hline & 15,0 & $80,0^{a}$ & $29,15^{\mathrm{a}}$ & 3,81 & $626,8^{b}$ & $3,22^{c}$ & $4,84^{b}$ \\
\hline & 22,5 & $67,5^{a b}$ & $27,87^{\mathrm{a}}$ & 3,69 & $117,2^{\mathrm{c}}$ & $0,71^{d}$ & $0,93^{\mathrm{c}}$ \\
\hline & 30,0 & $70,0^{a b}$ & $25,99^{a}$ & 3,89 & $137,1^{\mathrm{c}}$ & $0,80^{\mathrm{d}}$ & $1,16^{\mathrm{c}}$ \\
\hline & Ortalama & $71,5^{\mathrm{AB}}$ & $29,23^{\mathrm{CD}}$ & $3,60^{\mathrm{AB}}$ & $681,0^{C D}$ & $4,69^{\mathrm{AB}}$ & $4,59^{\mathrm{ABC}}$ \\
\hline \multirow{6}{*}{4} & 0 & $97,5^{a}$ & $49,96^{\mathrm{ab}}$ & 2,05 & $1701,1^{\mathrm{a}}$ & $8,35^{\mathrm{a}}$ & $9,03^{\mathrm{a}}$ \\
\hline & 7,5 & $100,0^{\mathrm{a}}$ & $41,50^{\mathrm{ab}}$ & 2,52 & $1814,5^{\mathrm{a}}$ & $8,97^{\mathrm{a}}$ & $9,17^{\mathrm{a}}$ \\
\hline & 15,0 & $97,5^{a}$ & $32,06^{b}$ & 3,13 & $1281,2^{b}$ & $6,22^{b}$ & $7,01^{b}$ \\
\hline & 22,5 & $32,5^{c}$ & $71,42^{\mathrm{a}}$ & 1,81 & $21,2^{c}$ & $0,10^{c}$ & $0,52^{\mathrm{c}}$ \\
\hline & 30,0 & $52,5^{b}$ & $61,63^{a b}$ & 1,78 & $74,2^{c}$ & $0,53^{c}$ & $0,85^{\mathrm{c}}$ \\
\hline & Ortalama & $76,0^{A}$ & $51,32^{A}$ & $2,26^{\mathrm{E}}$ & $978,4^{A}$ & $4,83^{\mathrm{AB}}$ & $5,31^{A}$ \\
\hline \multirow{6}{*}{5} & 0 & $85,0^{a}$ & $22,76^{b}$ & 4,66 & $1287,3^{\mathrm{a}}$ & $7,31^{a}$ & $6,85^{\mathrm{a}}$ \\
\hline & 7,5 & $67,5^{a}$ & $24,58^{b}$ & 4,19 & $703,2^{b}$ & $4,44^{a b}$ & $5,96^{\mathrm{a}}$ \\
\hline & 15,0 & $82,5^{\mathrm{a}}$ & $30,41^{a b}$ & 3,41 & $682,0^{b}$ & $2,59^{b c}$ & $5,78^{\mathrm{a}}$ \\
\hline & 22,5 & $22,5^{b}$ & $36,78^{a b}$ & 2,87 & $22,0^{c}$ & $0,18^{c}$ & $0,56^{b}$ \\
\hline & 30,0 & $15,0^{b}$ & $54,58^{a}$ & 2,41 & $13,1^{\mathrm{c}}$ & $0,08^{c}$ & $0,54^{b}$ \\
\hline & Ortalama & $54,5^{D}$ & $33,83^{\text {BCD }}$ & $3,51^{\mathrm{AB}}$ & $541,5^{\mathrm{DE}}$ & $2,92^{\mathrm{C}}$ & $3,94^{\mathrm{CD}}$ \\
\hline \multirow{6}{*}{6} & 0 & $92,5^{a}$ & $28,76^{\mathrm{a}}$ & 3,55 & $1631,9^{\mathrm{a}}$ & $9,72^{a}$ & $7,92^{\mathrm{a}}$ \\
\hline & 7,5 & $90,0^{a}$ & $33,04^{\mathrm{a}}$ & 3,10 & $1531,8^{\mathrm{a}}$ & $9,10^{a}$ & $7,62^{a}$ \\
\hline & 15,0 & $92,5^{\mathrm{a}}$ & $32,89^{\mathrm{a}}$ & 3,23 & $870,6^{b}$ & $3,93^{b}$ & $5,65^{b}$ \\
\hline & 22,5 & $52,5^{b}$ & $35,26^{\mathrm{a}}$ & 2,89 & $110,4^{\mathrm{c}}$ & $0,92^{c}$ & $1,13^{\mathrm{c}}$ \\
\hline & 30,0 & $55,0^{b}$ & $31,14^{\mathrm{a}}$ & 3,23 & $131,6^{\mathrm{c}}$ & $1,03^{c}$ & $1,18^{\mathrm{c}}$ \\
\hline & Ortalama & $76,5^{A}$ & $32,22^{\mathrm{CD}}$ & $3,20^{\mathrm{AB}}$ & $855,3^{B}$ & $4,94^{\mathrm{AB}}$ & $4,70^{\mathrm{ABC}}$ \\
\hline \multirow{6}{*}{7} & 0 & $42,5^{\mathrm{a}}$ & $34,47^{\mathrm{a}}$ & 3,04 & $187,8^{b c}$ & $1,95^{\mathrm{ab}}$ & $2,48^{\mathrm{ab}}$ \\
\hline & 7,5 & $47,5^{a}$ & $32,56^{a}$ & 3,42 & $514,9^{\mathrm{ab}}$ & $3,97^{\mathrm{a}}$ & $4,815^{\mathrm{a}}$ \\
\hline & 15,0 & $70,0^{a}$ & $28,35^{a}$ & 3,63 & $623,5^{\mathrm{a}}$ & $3,81^{\mathrm{a}}$ & $4,995^{\mathrm{a}}$ \\
\hline & 22,5 & $57,5^{a}$ & $37,17^{\mathrm{a}}$ & 2,83 & $107,8^{\mathrm{c}}$ & $0,67^{a}$ & $0,75^{b}$ \\
\hline & 30,0 & $67,5^{a}$ & $32,19^{\mathrm{a}}$ & 3,15 & $141,9^{\mathrm{c}}$ & $1,00^{b}$ & $1,03^{b}$ \\
\hline & Ortalama & $57,0^{C D}$ & $32,95^{\mathrm{CD}}$ & $3,22^{\mathrm{AB}}$ & $315,2^{\text {FG }}$ & $2,28 \quad$ EFG & $2,815^{\mathrm{EF}}$ \\
\hline
\end{tabular}


Çizelge 3, devamı

\begin{tabular}{|c|c|c|c|c|c|c|c|}
\hline Bakteri No & $\begin{array}{c}\text { Al Stress } \\
(\mathbf{m M})\end{array}$ & $\begin{array}{c}\text { ÇO } \\
(\%)\end{array}$ & ÇHK & $\begin{array}{r}\text { OÇZ } \\
\text { (gün) }\end{array}$ & ÇGI & $\begin{array}{l}\mathbf{K U} \\
(\mathbf{c m})\end{array}$ & $\begin{array}{l}\text { SU } \\
(\mathbf{c m})\end{array}$ \\
\hline \multirow{6}{*}{8} & 0 & $90,0^{\mathrm{a}}$ & $27,85^{\mathrm{ab}}$ & 3,77 & $1701,8^{\mathrm{a}}$ & $9,97^{\mathrm{a}}$ & $8,60^{\mathrm{a}}$ \\
\hline & 7,5 & $87,5^{\mathrm{a}}$ & $39,79^{\mathrm{a}}$ & 2,53 & $1527,4^{\mathrm{a}}$ & $8,80^{\mathrm{a}}$ & $8,55^{\mathrm{a}}$ \\
\hline & 15,0 & $72,5^{a}$ & $32,58^{\mathrm{ab}}$ & 3,1 & $92,2^{b}$ & $0,37^{\mathrm{c}}$ & $0,83^{b}$ \\
\hline & 22,5 & $22,5^{b}$ & $22,27^{b}$ & 2,56 & $53,3^{b}$ & $0,51^{\mathrm{c}}$ & $0,94^{b}$ \\
\hline & 30,0 & $35,0^{b}$ & $30,35^{\mathrm{ab}}$ & 3,55 & $433,8^{b}$ & $4,53^{b}$ & $7,96^{\mathrm{a}}$ \\
\hline & Ortalama & $61,500^{B C D}$ & $30,57^{C D}$ & $3,11^{B C}$ & $761,7^{\mathrm{BC}}$ & $4,83^{B C D}$ & $5,37^{\mathrm{A}}$ \\
\hline \multirow{6}{*}{9} & 0 & $65,0^{\mathrm{a}}$ & $33,03^{a}$ & 3,15 & $583,3^{a}$ & $4,24^{\mathrm{ab}}$ & $4,06^{\mathrm{a}}$ \\
\hline & 7,5 & $65,0^{\mathrm{a}}$ & $31,89^{\mathrm{a}}$ & 3,18 & $663,1^{\mathrm{a}}$ & $4,66^{\mathrm{a}}$ & $5,28^{\mathrm{a}}$ \\
\hline & 15,0 & $70,0^{a}$ & $25,72^{a}$ & 3,93 & $629,0^{a}$ & $2,87^{\mathrm{a}}$ & $5,91^{a}$ \\
\hline & 22,5 & $40,0^{b}$ & $30,72^{a}$ & 3,30 & $76,4^{b}$ & $0,58^{\mathrm{bc}}$ & $1,08^{b}$ \\
\hline & 30,0 & $32,5^{\mathrm{b}}$ & $25,86^{\mathrm{a}}$ & 3,95 & $24,6^{\mathrm{b}}$ & $0,23^{\mathrm{c}}$ & $0,51^{\mathrm{b}}$ \\
\hline & Ortalama & $54,50^{D}$ & $29,45^{C D}$ & $3,51^{A B}$ & $395,3^{\mathrm{EF}}$ & $2,51^{\mathrm{G}}$ & $3,37^{\mathrm{DE}}$ \\
\hline \multirow{6}{*}{10} & 0 & $72,5^{\mathrm{a}}$ & $28,23^{a}$ & 3,72 & $622,2^{a}$ & $3,87^{\text {a }}$ & $4,22^{\mathrm{ab}}$ \\
\hline & 7,5 & $62,5^{\mathrm{ab}}$ & $32,14^{\mathrm{a}}$ & 3,19 & $567,6^{a b}$ & $3,77^{\text {a }}$ & $5,06^{\mathrm{a}}$ \\
\hline & 15,0 & $40,0^{b}$ & $22,73^{a}$ & 4,58 & $244,6^{\mathrm{bc}}$ & $1,87^{\mathrm{ab}}$ & $3,15^{b}$ \\
\hline & 22,5 & $37,5^{b}$ & $28,35^{\mathrm{a}}$ & 3,75 & $70,3^{c}$ & $0,68^{\mathrm{b}}$ & $0,93^{\mathrm{c}}$ \\
\hline & 30,0 & $57,5^{\mathrm{ab}}$ & $27,97^{\mathrm{a}}$ & 3,63 & $100,8^{c}$ & $0,90^{\mathrm{ab}}$ & $0,84^{\mathrm{c}}$ \\
\hline & Ortalama & $54,00^{D}$ & $27,89^{D}$ & $3,78^{A}$ & $321,1^{\mathrm{FG}}$ & $2,22^{\text {DEFG }}$ & $2,84^{\mathrm{EF}}$ \\
\hline \multirow{6}{*}{11} & 0 & $95,0^{a}$ & $30,96^{\mathrm{a}}$ & 3,27 & $2028,8^{a}$ & $12,33^{\mathrm{a}}$ & $8,96^{\mathrm{a}}$ \\
\hline & 7,5 & $100,0^{a}$ & $33,05^{\mathrm{a}}$ & 3,07 & $1770,0^{b}$ & $10,06^{b}$ & $7,64^{\mathrm{ab}}$ \\
\hline & 15,0 & $92,5^{\text {a }}$ & $33,73^{a}$ & 3,06 & $1126,1^{\mathrm{c}}$ & $4,72^{\mathrm{c}}$ & $7,44^{b}$ \\
\hline & 22,5 & $30,0^{b}$ & $30,41^{\mathrm{a}}$ & 3,33 & $60,9^{\mathrm{d}}$ & $0,46^{\mathrm{d}}$ & $1,14^{\mathrm{c}}$ \\
\hline & 30,0 & $37,5^{b}$ & $28,40^{\mathrm{a}}$ & 3,56 & $34,4^{\mathrm{d}}$ & $0,23^{d}$ & $0,56^{\mathrm{c}}$ \\
\hline & Ortalama & $71,00^{A B}$ & $31,33^{C D}$ & $3,26^{\mathrm{AB}}$ & $1004,0^{A}$ & $5,56^{\mathrm{BCDE}}$ & $5,15^{\mathrm{AB}}$ \\
\hline \multirow{5}{*}{$\begin{array}{c}\text { Al uygulama } \\
\text { ortalamas1 }\end{array}$} & 0 & $80,6^{a}$ & $31,95^{b}$ & $3,35^{\mathrm{a}}$ & $1230,9^{a}$ & $7,37^{\mathrm{a}}$ & $6,67^{a}$ \\
\hline & 7,5 & $75,2^{\mathrm{a}}$ & $35,56^{\mathrm{ab}}$ & $3,05^{\mathrm{ab}}$ & $1082,9^{b}$ & $6,63^{b}$ & $6,59^{a}$ \\
\hline & 15,0 & $77,1^{\text {a }}$ & $32,10^{b}$ & $3,34^{\mathrm{a}}$ & $684,7^{\mathrm{c}}$ & $3,25^{\mathrm{c}}$ & $5,09^{b}$ \\
\hline & 22,5 & $39,8^{b}$ & $38,10^{\mathrm{a}}$ & $2,78^{b}$ & $72,1^{d}$ & $0,58^{\mathrm{d}}$ & $0,89^{d}$ \\
\hline & 30,0 & $43,3^{b}$ & $34,52^{\mathrm{ab}}$ & $3,14^{\mathrm{ab}}$ & $101,8^{\mathrm{d}}$ & $0,88^{\mathrm{d}}$ & $1,38^{\mathrm{c}}$ \\
\hline
\end{tabular}

* Aynı harfle gösterilen ortalamalar arasındaki farklar kendi grubunda önemli $(\mathrm{p}<0.01)$ değildir.

\section{TARTIŞMA}

Ağır metaller bitki dokularında aşırı biriktiği zaman canlılıkla ilgili çeşitli büyüme süreçleri değişebilmektedir (Phalsson,, 1989). Bunlara örnek olarak mineral beslenme (Costa et al., 1994), transpirasyon (Lidon et al., 1993), fotosentez (Nussbaum et al., 1988), enzim aktivitesi (Doncheva et al., 1996), nükleik asit yapısı (Somashekaraiah et al., 1992), klorofil biyosentezi (Munzuroğlu ve Geçkil, 2002) ve çimlenme (Ouzounidou et al., 1992) gibi bitki metabolizmasındaki önemli olayların değişmesine sebep olur. Bunlara ek olarak membran hasarı, hormon dengesinin bozulması ve su ilişkisinin değişmesi gibi fizyolojik olaylar da etkilenebilmektedir (Kennedy and Gonsalves, 1987). Genellikle toksik özelliğe sahip olan ağır metaller çeşitli kaynaklardan çevreye yayılmakta ve günümüzde çevre kirliliğinin önemli nedenlerinden birini oluşturmaktadır (Goyer, 1991).

Araştırma sonucunda Al konsantrasyonundaki artışa bağlı olarak çimlenme oranı, çimlenme hızı katsayısı, çimlenme gücü indeksi, sürgün uzunluğu ve kök uzunluğu azalmış; ortalama çimlenme zamanını ise uzamıştır. Kontrole kıyasla, 4 nolu bakteri (Pseudomonas fluorescens 8/6) aşılaması, ortalama çimlenme zamanı dışındaki, ölçümü yapılan parametreler bakımından daha iyi sonuçlar vermiştir. Bitkilerin ağır metal toksisitesine karşı toleransları bitki türüne, element türüne, strese maruz kalma süresine ve strese maruz kalan doku veya organın yapısına bağlı olarak değişmektedir. Bu nedenle ağır metalin tür ve miktarı, yarayışlılığı, zararın şiddeti ve türü ayrıca zarar oluşum sürecinin bilinmesi bitkilerin gelişimi ve canlılığı açısından oldukça önemlidir (Öktüren ve Sönmez, 2007). Diğer taraftan, bakteri uygulaması, özellikle $\mathrm{Al}$ ile oluşturulan stresin olumsuz etkilerini azaltmış, tohum çimlenme oranı ve kök ve sürgün uzunluğunu artırmış; çimlenme süresini ise kısaltmıştır. Toprakta, suda ve havada doğal olarak bulunan alüminyum, doğa ve insan faaliyetleri ile çevreye girer (Wilkens et al., 1997). Alüminyum; bitkilerden, bitkisel 
metabolizmadan ve diğer metabolizma süreçlerinden serbest forma dönüşmektedir. Alüminyum toprak ve havadaki mikro parçacıklara karışabilir (Tangen, 1977). Alüminyum, düşük asitli ortamlarda toksisite gösteren ağır metal olmayan önemli elementlerden biridir. $\mathrm{Bu}$ nedenle, asidik toprakların çoğunda alüminyum toksisitesi vardır. Topraktaki asitlik, toprakta bulunan pek çok canlının çoğaltmasını engellemektedir. Bitkilerde görülen, toprak asitliğinin olumsuz etkisi kalsiyum eksikliği, alüminyum veya magnezyum toksisitesini içerir (Delhaize et al., 1995). Tarımda, alüminyum toksisitesi verim ve bitki büyümesinde azalmaya neden olmaktadır. Ayrıca, bitkilerde alüminyum konsantrasyonuna bağlı olarak insan vücuduna geçebilir ve insan sağlığında problemlere sebep olabilir (Tohidi et al., 2015).

Dünya'daki asidik toprakların çoğunda ve gıda ve bitkisel maddeler üretme potansiyeline sahip tarım arazilerinin yaklaşık \%70'inde, Al en önemli bitki büyüme sınırlandırma faktörüdür. Sonuç olarak, Al toksisitesi ve bitki toleransı ile ilgili bilimsel referanslar az da olsa tarla bitkilerine odaklanmıştır. Asit yağmurları ve bazı tarımsal uygulamalar tarım alanlarının asidik olmasına neden olur. Asidik topraklarda, $\mathrm{Al}$ ve $\mathrm{Mg}$ gibi bazı elementlerin çözünürlüğü artmakta ve sonuçta bitkilerde toksisite gözlenmektedir (Delhaize et al., 1995). Asidik kök ortamı, birçok besinin emiliminde dengesizliğe neden olur ve bitkilerin anormal büyümesine yol açar (Tohidi et al., 2015). Bu nedenle, kök çevresindeki asidik ortam bazı elementlerin sekonder toksisitesine neden olabilir (Tohidi et al., 2015). Toksik ve ağır metal alanlarında yapılan en önemli araştırmalar çoğunlukla Al ile ilgilidir. Bununla birlikte, bitkiler üzerindeki alüminyum toksisitesinin birçok yönü bilinmemektedir. Alüminyum asidik ortamlarda iyonik hale gelebilir ve toksisiteye neden olabilir. Bitkiler, alüminyum ve ağır metallerin stres altında, toksik iyonların kalıcı varlığı ve konsantratif toksisitenin neden olduğu hasarlar ile birlikte büyürler. Ortam stresinin belirtisi farklı düzeylerde zehirlenme şeklindedir. Alüminyum toksisitesi ve fosfor eksikliği, bitkilerin biyokimyasal ve fizyolojik gelişimi üzerinde çok daha fazla etkiye sahiptir. Alüminyum toksisitesinin, buğday, fasulye, soya ve benzeri kültür bitkilerinin yetiştiriciliğine olan etkisiyle ilgili birçok araştırmalar yapılmıştır (Amami, 1996). Bitki gelişimini teşvik eden bakteriler (PGPB) genelde bitkinin kök bölgesi yakınlarında ya da kök bölgesiyle doğrudan bağlantılı olarak kolonize olmaktadır. Daha çok Acetobacter, Acinetobacter, Achromobacter, Aereobacter, Agrobacterium, Alcaligenes, Artrobacter, Azospirillum, Azotobacter, Bacillus, Burkholderia, Clostridium, Enterobacter, Erwinia, Flavobacterium, Klebsiella, Micrococcus,
Pseudomonas, Rhizobium, Serratia ve Xanthomonas cinslerine ait bakteri guruplar1 strese tolaransta etkin rol oynamaktadırlar (Çakmakçı vd., 2006). Bu gibi bakteri gruplarının bitkilere farklı uygulama metotları kullanılarak uygulanması ile bitki ve bakteri arasında karşılıklı bir etkileşim oluşturmaktadır. Özellikle bitki kök bölgesinin \%7-15 gibi bir kısmını teşkil eden rizosfer bölgesinde yaşayan bakteriler (Pinton et al., 2001) bu bölgede salgılanan çeşitli aminoasit ve şekerleri zengin enerji ve besin kaynağ 1 olarak kullanmakta ve bu bölgeden sızan karbon (C) ve azot (N) kaynaklarından faydalanmaktadırlar. Bakterilerin bitkide göstermiş oldukları bu gibi etkileşimler, bitki rizosfer bölgesinde rekabetçi bir ortam oluşturarak bitki gelişimini uyarmakta, ayrıca biyokontrol sağlayarak faydalı bir etki göstermektedir (Bhattacharyya and Jha, 2012).

Al'in toksisitesi, kök uzamasını sınırlandırarak, mahsul verimliliğini etkiler, bu da besin ve suyun alınmasını azaltarak tüm bitkinin büyümesini azaltır (Kochian, 1995; Goodwin and Sutter, 2009; Ma et al., 2012). Bitkinin Al'in toksisitesini tolere ettiği birçok fizyolojik mekanizma rapor edilmiştir. Bitkilerin Al toleransı iç ve dış tolerans olarak iki şekildedir. Dış tolerans, çevresel Al iyonlarını şelatlamak ve bitkiye ulaşımının engellenmesi için kök hücreden rizosfere organik asitlerin üretilmesiyle gerçekleştirilir (Magalhaes et al., 2007; Ryan et al., 2005; Delhaize et al., 1995). İç tolerans ise, Al iyonlarının sürüklenmesiyle ve bitki hücre duvarlarında veya plazma membranında ya da bitki hücresinin içinde, hassas dokulardan uzak olan vakuollarda sıkışması ile oluşur (Kochian, 1995; Ramgareeb et al., 1999). Genel olarak, mikrobiyal popülasyon bitki verimini etkileyen potansiyel etkilere sahiptirler. Bazıları bitki büyümesini teşvik etmek için gübre; bazıları ise hastalık ve zararlılara karşı bitkileri korumak için biyopestisit olarak kullanılmaktadır. Bu tip seçici mikrobiyal izolatlar PGPB olarak adlandırılır. PGPB, bitkiler ile özel simbiyotik benzeri ilişkisi olan bakterilerdir (Bashan and de-Bashan, 2002). PGPB farklı çevresel konumlardan izole edilen bakteriyel izolatlardır ve bitki büyüme parametrelerini olumlu yönde doğrudan veya dolaylı olarak etkilemektedir. Doğrudan mekanizmalar, biyolojik azot fiksasyonu, giberallin, sitokinin oksinler gibi bitkisel hormonların üretilmesi, çevresel stresi azaltma, bakteri-bitki ilişkisinde uyum, siderophor üreterek demir elementinin alınabilirliliğinin arttırılması ve diğer bazı iz elementlerde artış sağlama, inorganik fosforun çözünmesi ve organik fosfor bileşiklerinin mineralizasyonu, vitamin sentezi, kök geçirgenliğini artırma gibi etkileri içermektedir (Tsavkelova et al., 2006; Vassilev et al., 2006; Çakmakçı vd. 2017). 


\section{SONUC}

Bu çalışmada Pseudomonas fluorescens bakteri uygulamasının yukarıda belirtilen buğdayın çimlenme karakterleri bakımdan alüminyumun olumsuz etkisinin azaltılmasında etkili olduğu belirlenmiştir. Test edilen bakteri streinlerine bağlı olarak değişmekle birlikte etkin bakterilerin $\mathrm{Al}$ toksiditesi ve benzeri metal toksikliğinin belli ölçüde tolera edilmesi bakımından önemli olabileceği ve bu konuda daha ileri araştırmalara gerek olduğu ortaya çıkmıştır.

\section{KAYNAKLAR}

Abdul-Baki, A.A., Anderson, J.D., 1970. Viability and leaching of sugars from germinating barley. Crop Sci., 10 (1): 31-34.

Amami A. 1996. Methods of plant analysis. 972: 248, Soil conservation 1: 177-196.

AOSA., 1983. Seed vigor testing handbook. Contibution No.32 to the handbook on seed testing. Association of Official Seed Analysts.

Baker, A.J.M., McGrath, S.P., Reeves, R.D., Smith, J.A.C. 2000. Metal hyperaccumulator plants: A review of the ecology and physiology of a biological resource for phytoremediation of metal-polluted soils. In Terry, N., Banuelos, G. (eds.) Phytoremediation of Contaminated Soil and Water, Lewis Publisher, Boca Raton. 85-107.

Barzanti, R., Ozino, F., Bazzicalupo, M., Gabbrielli, R., Galardi, F., Gonnelli, C., Mengoni, A., 2007. Isolation and characterization of endophytic bacteria from the nickel hyperaccumulator plant Alyssum bertolonii. Microb. Ecol., 53: 306-316.

Bashan, Y., de-Bashan, L.E., 2002 . Protection of tomato seed - lings against infection by Pseudomonas syringae pv. Tomato by using the plant growthpromoting bacterium Azospirillum brasilense. Appl. Environ. Microbiol., $68: 2637-2643$.

Belimov, A., Hontzeas, N., Safronova, V., Demchinskaya, S., Piluzza, G., Bullitta, S., Glick, B., 2005. Cadmium-tolerant plant growth-promoting bacteria associated with the roots of Indian mustard (Brassica juncea L. Czern.). Soil Biol. Biochem., 37: 241-250.

Benmalek, Y., Halouane, A., Hacene, H., Fardeau, M.-L., 2016. 2014. Resistance to heavy metals and bioaccumulation of lead and zinc by Chryseobacterium solincola strain 1YBR12T isolated from soil. Int. J. Environ. Engin., 6: 68-77.

Bhattacharyya, P.N., Jha, D.K., 2012. Plant growthpromoting rhizobacteria (PGPR): emergence in agriculture. World J Microbiol Biotechnol., 28(4): 1327-1350.

Costa, J.M., Kronstad, W.E.,1994. Association of grain protein concentration and selected traits in hard red winter wheat populations in the Pacific Northwest. Crop Sci., 34: 1234-1239.

Çakmakçi, R., Dönmez, F., Aydin, A., Sahin, F., 2006. Growth promotion of plants by plant growthpromoting rhizobacteria under greenhouse and two different field soil conditions. Soil Biol. Biochem., 38: 1482-1487.

Çakmakçı, R., Turan, M., Kıtır, N., Güneş, A., Nikerel, E., Özdemir, B.S., Yıldırım, E., Olgun, M., Topçuoğlu, B., Tüfenkçi, Ş., Karaman, M.R., Tarhan, L., Mokhtari, N.E.P., 2017. In: Wanyera, R., Owuoche, J. (eds.), The Role of Soil Beneficial Bacteria in Wheat Production: A Review. Wheat Improvement, Management and Utilization. In Tech. Rijeka, Croatia - European Union, 115-149.

Delhaize, E., Craig, S., Beaton, CD., Bennet, RJ., Jagadish, VC., Randall, PJ., 1995. Aluminum tolerance in wheat (Triticum aestivum L.). I. Uptake and distribution of aluminum in root apices. Plant Physiol., 103: 685-693.

Dell'Amico, E., Cavalca, L., Andreoni, V., 2005. Analysis of rhizobacterial communities in perennial Graminaceae from polluted water meadow soil, and screening of metalresistant, potentially plant growthpromoting bacteria. FEMS Microbiol. Ecol., 52:153162.

Dezfuli, P. M., Sharif-Zadeh, F., Janmohammadi, M., 2008. Influence of priming techniques on seed germination behavior of maize inbred lines (Zea mays L.). JABS, 3: 22-25.

Doncheva, S., Nicolov, B., Ogneva, V., 1996. Effect of copper excess on the morphology of the nucleus in maize root meristem cells, Phsiol. Plantarum., 96: 118-122.

Foy, CD., Duke, JA., Devine, TE .,1992. Tolerance of soybean germplasm to an acid tatum subsoil. J. Plant Nutr., 15: 527-547.

Goodwin, S.B., Sutter, T.R., 2009. Microarray analysis of Arabidopsis genome response to aluminum stress. Biol. Plant., 53:85-99.

Goyer, R.A., Miller, C.R., Zhu, S.Y., Victery, W., 1991. Non-metallothionein bound cadmium in the pathogenesis of cadmium nephropathy in the rat. Toxicol. Appl. Pharmacol., 101: 232-244.

Harborne, J.B., 1984. Methods of plant analysis. In Phytochemical methodspp.1-36. Springer, Dordrecht.

Heinonsalo, J., Frey-Klett, P., Pierrat, J.C., Churin, JL., Vairelles, D., Garbaye J., 2004. Fate, tree growth effect and potential impact on soil microbial communities of mycorrhizal and bacterial inoculation in a forest plantation. Soil Biol Biochem., 36: 211-216.

Idris, R., Trifonova, R., Puschenreiter, M., Wenzel, W.W., Sessitsch, A., 2004. Bacterial communities associated with flowering plants of the $\mathrm{Ni}$ hyperaccumulator Thlaspi goesingense. Appl. Environ. Microbiol., 70: 2667-2677.

Jiang, C-y., Sheng, X-f., Qian, M., Wang, Q-y., 2008. Isolation and characterization of a heavy metalresistant Burkholderia sp. from heavy metalcontaminated paddy field soil and its potential in promoting plant growth and heavy metal accumulation in metal-polluted soil. Chemosphere., 72: $157-164$

Kennedy, C.D., Gonsalves, F.A.N., 1987. The action of divalent zinc, cadmium, mercury, copper and lead on 
the trans-root potential and $\mathrm{H}^{+}$efflux of excised roots. J. Exp. Bot., 38(5): 800-817.

Kochian LV ., 1995 .Cellular mechanisms of aluminum toxicity and resistance in plants. Annu Rev Plant Physiol Plant Mo1 Biol., 46:237-260.

Kuffner, M., De Maria, S., Puschenreiter, M., Fallmann, K., Wieshammer, G., Gorfer, M., Strauss, J., Rivelli, A.R, Sessitsch, A., 2010. Culturable bacteria from Zn-and Cd-accumulating Salix caprea with differential effects on plant growth and heavy metal availability. J. Appl. Microbiol., 108: 1471-1484.

Lidon, F.C., Ramalho, J., Henriques, F.S.,1993. Copper inhibition of rice photosynthesis. J. Plant Physiol., 142: $12-17$

Ma, L., Ahuja, L.R., Nolan, B.T., Malone, R.W., Trout, T.J., Z. Qi., 2012. Metim içinde farklı gösterilmiş Root zone water quality model (RZWQM2): Model use, calibration and validation. Trans. ASABE, 55: 1425-1446.

Magalhaes, J.V., Liu, J., Guimaraes, C.T., et al., 2007. A gene in the multidrug and toxic compound extrusion (MATE) family confers aluminum tolerance in sorghum. Nature Genet., 39:1156-1161.

Maguire, J.D., 1962. Speed of germination-aid in selection and evaluation for seedling emergence and vigor. Crop. Sci., 2:176-177.

Munzuroglu, O., Geckil, H. 2002. Effects of metals seed germination, root elongationand coleoptiles and hypocotyls growth in Triticum aestivum and Cucumis sativus. Arch. Environ. Contam. Toxicol., 43, 61-73.

Nussbaum, S., Schmutz, D., Brunold, C., 1988. Regulation of assimilatory sulfate reduction by cadmium in Zea mays L. Plant Physiol., 88:1407-1410.

Mengel, K., Kirkby, E.A., 1978. Principles of plant nutrition. Principles of plant nutrition. Springer, Dordrecht.

Ouzounidou, G., Eleftheriou, E.P., Karataglis, S., 1992. Ecophysical and ultrasturctural effects of copper in Thlaspi ochroleucum (Cruciferae). Can. J. Bot., 70: 947-957.

Öktüren Asri, F., Sönmez, S., 2007. Ağır metal toksisitesinin bitki metabolizması üzerine etkileri. Derim., 23: 36-45.

Phalsson, A.M.B., 1989. Toxicity of heavy metals ( $\mathrm{Zn}, \mathrm{Cu}$, $\mathrm{Cd}, \mathrm{Pb})$ to vascular plants. Water, Air, Soil Pollut., 47: 287-19.
Pinton, R., Varanini, Z., Nannipieri, P., 2001. The Rhizosphere as a site of biochemical interactions among soil components, plants, and microorganisms. In: Pinton R, Vranini Z, Nannipieri P., Eds. The rhizosphere biochemistry and organic substances at the soil-plant interface. Marcel Dekker, New York, pp 1-17.

Ramgareeb, S., Watt, M.P., Marsh, C., Cooke, J.A., 1999. Assessmentof $\mathrm{Al}^{3+}$ availability in callus culture media for screening tolerant genotypes of Cynodon dactylon. Plant Cell Tiss. Org. Cult., 56: 65-68.

Ryan, J.P., Chavez, F.P., Bellingham, J.G., 2005. Physicalbiological coupling in Monterey Bay, California:Topographic influences on phytoplankton ecology. Mar.Ecol. Prog. Ser., 287: 23-32.

Schiller, N.G., Basch, L., Blanc, C.S., 1995. From 1mmigrant to transmigrant: theorizing transnational migration. Med Anthropol Q., 68(1): 48-63.

Somashekaraiah, B.V., Padmaja, K., Prasad, A.R.K., 1992. Phytotoxicity of cadmiumions on germinating seedlings of mung bean (Phsalis vulgaris) involvement of lipid peroxides in chlolophyll degradation. Plant Pathol., 85:85-89.

Stresty, T.V.S., Madhava Rao, K.V.M., 1999. Ultrastructural alterations in response to zinc and nickel stress in the root cell of pigeonpea. Environ. Exp, Bot., 41: 3-13.

Tangen, K ., 1977. Blooms of Gyrodinium aureolum (Dinophyceae) in north European waters, accompanied by mortality in marine organisms. Sarsia., 63:123 - 133.

Tsavkelova, E.A., Klimova, S.Yu., Cherdyntseva, T.A., Netrusov, A.I.,2006. Miccrobial producers of plant growth stimulators and their practical use: A review. Appl. Biochem. Microbiol., 42:117-126.

Tohidi, Z., Baghizadeh, A., Shekofeh Enteshari, S., 2015. The Effects of Aluminum and Phosphorous on some of Physiological Characteristics of Brassica napus. J. Stress Physiol.Biochem. 11: 16-28

Vassilev, D., Nenov, A., Atanassov, A., Dimov, G., Getov, L., 2006. Application of bioinformatics infruit plant breeding. J. Frutt Ornam Plant Res., 14:145-162.

Wilkens, B.J., and Loch, J.P.G., 1997. Accumulation of cadmium and zinc from diffuse emission on acid sandy soils, as a function of soil composition. Water, Air, Soil Pollut., 96:1-16. 